\title{
FRIDA: UM ÍCONE PARA A MODA SOB O OLHAR DA PSICANÁLISE
}

\author{
Roberto Francisco Abreu \\ Escola de Design - Universidade Veiga de Almeida \\ roberto.abreu@uva.br \\ Lucilia Tristão Ramos \\ Escola de Design - Universidade Veiga de Almeida \\ lucilia.ramos@uva.br
}

Resumo: O presente artigo visa a interlocução entre o ato do se vestir, a moda e a psicanálise. Tem como objetivo investigar a influência da vestimenta no processo de constituição de uma imagem corporal com a qual o usuário se identifica apresentando como objeto de estudo Frida Kahlo. Utilizando-se de alguns conceitos de Lacan e Freud, busca compreender o comportamento humano em relação às suas escolhas, que compõem sua identidade corporal, ou melhor, seu eu. Procura estabelecer pontos de encontro para conectar o poder formativo da imagem na constituição do eu-corpo e as relações com o espelho e o outro, entendido como os grupos de moda, a cultura e as experiências humanas.

Palavras-chave: Moda, psicanálise, constituição do eu, identificação, criação.

\begin{abstract}
This article aims to dialogue between the act of dressing, fashion and psychoanalysis. It aims to investigate the influence of dress in the process of constitution of a body image with which the user is identified as presenting object of study Frida Kahlo. Using some concepts of Lacan and Freud seeks to understand human behavior in relation to their choices, that make up your body identity, or rather its "self. It seeks to establish meeting points for connecting the formative power of the image in the constitution of the self - body and the relationship with the mirror and the other, understood as the fashion groups, culture and human experience.
\end{abstract}

Keywords: Fashion, psychoanalysis, constitution of self, identification, creation. 


\section{INTRODUÇÃO}

A formação do eu por meio dos processos de criar e de vestir faz parte da comunicação, tanto verbal, quanto não verbal e segue em amplitude.

As investigações sobre a subjetivação na história da psicanálise ganharam contornos que marcaram de forma definitiva a contemporaneidade. Desse arcabouço teórico e epistêmico desponta Sigmund Freud, no final do século XIX, trazendo uma proposição que marcaria para sempre a humanidade: o conceito do inconsciente. $A$ subjetividade, antes pensada una com Descartes, é dividida. A presença de algo no sujeito que ele desconhece em si mesmo, que aparece nos sonhos, nos atos falhos, nos sintomas, sem razões físicas; é a divisão peculiar entre sujeito e eu, consciente e inconsciente.

Nos anos 1930, outro grande estudioso da área, Jacques Lacan, avançou em suas teses fazendo um retorno à obra de Freud, aproximando-se da linguística estrutural de Ferdinand de Saussure, e se apropriando de alguns conceitos que mudariam a história da psicanálise. Lacan (1964) enuncia que o inconsciente é estruturado como uma linguagem e o sujeito é dependente dela.

Através do ícone Frida Kahlo, o estudo apresenta a vestimenta como formadora de um novo ser. Aponta como ela é capaz de acionar e potencializar nos sujeitos, processos criadores de novos modos de existir, de novas singularidades. O indivíduo se transforma através da sua "segunda pele" e esta relação entre o eu e a roupa se faz como meio de identificação despertando uma coleção de sentimentos, imagens e cores, construindo personagens.

A artista plástica é o exemplo abordado para a compreensão de como o humano encontra e reencontra o seu eu a partir da vestimenta.

O estudo propõe a reflexão sobre a formação do eu, a partir do ato de vestir e da criação como suporte para acionar e potencializar nos sujeitos processos criadores de novos modos de existir, novos modos de viver, novos estilos, novas formas de si, enfim, de fazer emergir singularidades tendo a psicanálise como uma interlocutora.

\section{FRIDA E O ESPELHO}

Pode-se considerar que a criação de moda opera como algo capaz de formar, ou, no mínimo, sugerir novas identidades. A partir do momento em que o humano se identifica, faz do outro um espelho, transformando-se.

Frida Kahlo é um bom exemplo dessa reflexão, sendo ela uma mulher que mudou diversas vezes de identidade, seguindo uma direção contrária à moda e aos padrões de sua época e que, ao longo da sua vida, foi sua própria inspiração e posteriormente, atingiu a linguagem de um grande público, virando tendência de moda.

Segundo Flores (2010, p.130):

Kahlo cultivou e promoveu a ambiguidade que a sua (obra) produzia: ao converter sua figura pública (Frida, a mulher de Diego) em uma 
representação (Frida=imagem), sua obra plástica começou a se constituir um espelho literal de sua construção imaginária (Obra=imagem de Frida). Buscar encontrar a verdadeira Frida no personagem de "Frida" é tão absurdo quanto impossível: Frida não é uma pessoa real, e sim uma figura discursiva - um motivo temático - no nível da fala, da imagem ou da apresentação pública. Em um sentido amplo da palavra, Frida é uma imagem: uma produção da psique imaginária que cria incessante e continuamente o ser, e não uma evidência ou reflexo deste.

Frida nasceu em 1907, desde pequena fantasiava ser filha da Revolução Mexicana. Ficou conhecida por sua obra, em especial por seus autorretratos. Pintava em cores fortes suas dores e fez desse sofrimento sua própria linguagem. Sua memória da infância é de ter sido desprezada e feia; e sua perna fina se tornou o símbolo externo do seu "eu aleijado" (FLORES, 2010, p.126). Cresceu racionalizando suas ações e a relação peculiar que ela mantinha com a própria imagem, camuflava a ideia que fazia de si mesma criando uma espécie de máscara, expondo um anseio comum a todo ser humano: a tentativa de camuflar a falta de algum predicado, recorrendo à identificação com um personagem. Sendo assim, Frida revisitou a própria imagem constantemente.

A artista começou a pintar depois do acidente de bonde sofrido aos 16 anos. Em decorrência, precisou conviver com a frequente necessidade de estar em posição horizontal e, sendo assim, a artista começa a usar o objeto espelho afixado no teto acima de sua cama para pintar a sua própria imagem.

Apesar de sua vida curta (Frida viveu entre 1907 e 1954), a artista guiou-se em busca constante de um eu-ideal, tinha um estilo único que pertencia em primeiro lugar ao seu próprio olhar, refletindo seu lugar na sociedade como se declarasse: "sou humana, sou artista".

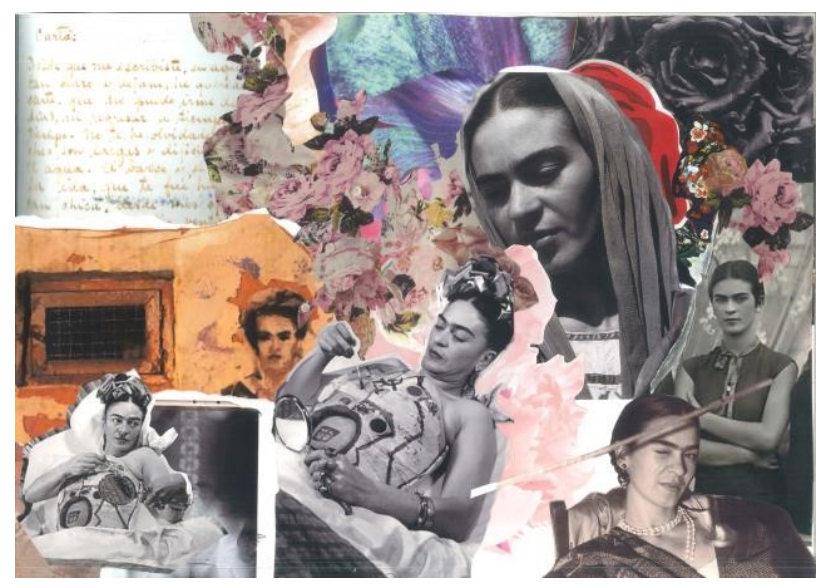

Figura 1: "Frida e os espelhos". Autor: Abreu, R.F. Técnica: Colagem, 2013.

Elaborado pelo autor, com base na pesquisa realizada.

Indiscutivelmente é figura-chave na Arte Latina do século $X X$, mas não se criou somente através dela, fez da sua veste a sua linguagem pictórica, uma maneira de se identificar e de se comunicar com o mundo. Seu desejo por independência e o seu modo de vestir a fizeram uma personagem marcante e controversa para sua época, 
uma personalidade que causava um certo desconforto e ao mesmo tempo que despertava interesse na sociedade.

Um dos primeiros momentos de metamorfose de Frida foi registrado por seu pai em uma foto de família, quando ainda era adolescente. Ela surpreendeu a todos quando apareceu, com olhar firme como quem queria mostrar uma força ficcional, usando um terno masculino, na tentativa talvez de afirmar-se como "à altura" dos homens: forte e revolucionária.

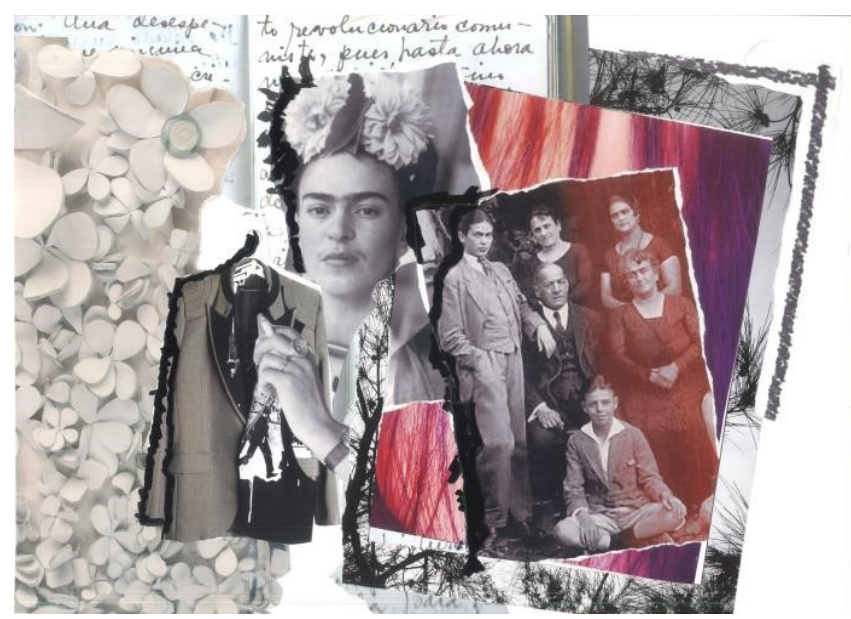

Figura 2: "Frida e o ideal masculino da Revolução".

Autor: Abreu, R.F. Técnica: Colagem, 2013. Elaborado pelo autor, com base na pesquisa realizada.

Outro momento foi registrado por ela mesma no conhecido Autorretrato de Cabelos Cortados, de 1940, e sobre o qual Herrera escreve:

Um clima de retaliação furiosa é expresso em Autorretrato de Cabelos Cortados, em que ela despiu as roupas tehuanas que Diego gostava que ela usasse e, em vez disso, veste um sóbrio terno masculino, de tonalidade escura, tão largo que deve ser de Diego. Ela está sentada com as pernas abertas, como um homem, e usa camisa e sapatos de amarrar masculinos. Os brincos são o único vestígio de feminilidade. (HERRERA, 1983, p.347)

Na época, Frida havia se separado de Diego Rivera, nesse autorretrato está, mais uma vez, uma metáfora da masculinidade, símbolo do poder fálico.

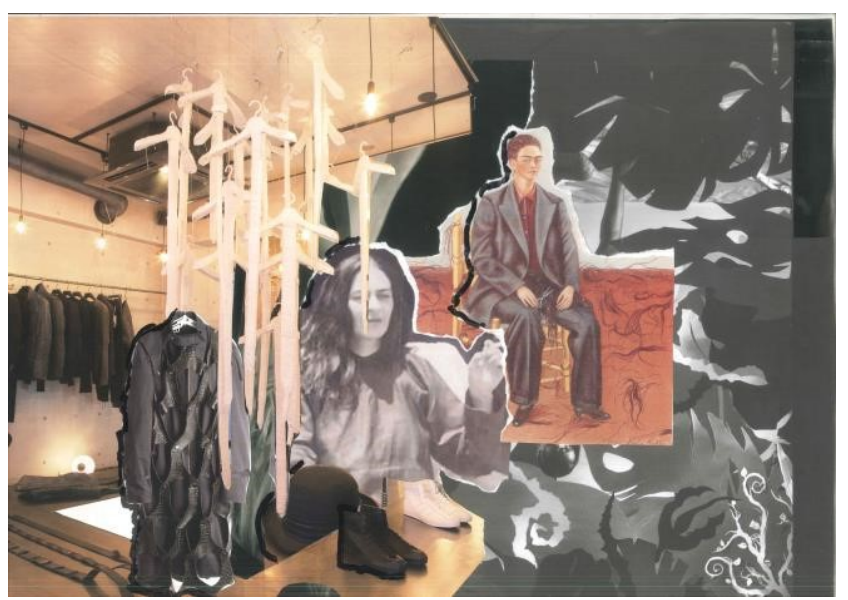

Figura 3: "Frida e o ideal masculino da revolta". Autor: Abreu, R.F. Técnica: Colagem, 2013.

Elaborado pelo autor, com base na pesquisa realizada. 
Este constante ir e vir dessa persona masculina, entre outras, apareceu diversas vezes em sua história de vida, conforme observa Souza:

Horácio Fernández, ao comentar um conjunto de fotos colecionadas por Frida, fala da multiplicidade de imagens produzidas por Frida, às vezes aparecendo de calças compridas, ou então coberta por velhos trajes e blusas bordadas fora de moda, sendo a maioria escolhidas com denominação de origem. (SOUZA, 2011, p. 89)

O ano de 1929 foi um marco na vida da artista. Na cerimônia de seu casamento, abandonou o traje tradicional branco por um vestido da sua criada indígena. Nesse momento evocando outra referência de ideal-do-eu onde transforma/cria uma nova personagem por meio da vestimenta.

Pode-se pensar no ideal-do-eu como o resgate da cultura mexicana, com o qual, Frida constituiu um eu-ideal. A criada mexicana era um outro "lugar" de onde Frida poderia se ver coletando traços significantes da sua cultura - os saiões, os xales, as cores vivas, as flores - para, hipoteticamente, compor roupas que funcionavam para ela como eu-ideal, ajudando assim a superar a sua falta em seu corpo deformado.

Em plenos anos 1930, uma época em que se usava vestidos alongados, Magdalena Carmem Frida, seguiu na contramão das tendências dominantes, desfilando uma personagem com roupas típicas tehuana ${ }^{1}$, decorativas, vivas, cheias de cor e autenticidade, e fazendo delas sua marca.

\title{
2.1 Frida e a moda
}

Enquanto Frida pintava seu eu obsessivamente, tornou-se uma figura pública extremamente popular, e aos poucos, uma referência de moda, por conta da comoção gerada por matérias de revistas desse segmento, registrando suas peculiaridades estilísticas. Sobre isso, Oriana Baddeley, historiadora e pesquisadora da University of the Arts de Londres, pincela o resultado dessas publicações:

\begin{abstract}
Os referenciais visuais nas duas revistas englobam tanto fotos da artista quanto os seus trabalhos. Nas duas edições, ela é apresentada como uma pessoa exótica, apaixonada e que constantemente teve que lutar contra a dor e a frustração. Enquanto a Elle, a Vogue e, mais tarde a The Independent, enfatizaram as diferentes facetas da sua persona, todas elas compartilharam da mesma opinião quanto ao seu "eu" - "eu" que seria a síntese do estereótipo das imagens do México - muito mais do que no seu trabalho em si. (tradução nossa) (BADDELEY, 1991, p.11)
\end{abstract}

Diante do desejo e necessidade de "recriar-se", Frida se utiliza das vestes, ou daquilo que veste seu corpo como coadjuvante, na busca pelo ser. Encontra ali uma das linguagens possíveis para se expressar, para se colocar no mundo. A maneira como transita no limiar desfocado entre arte e vida é perceptível em sua própria obra.

\footnotetext{
${ }^{1}$ Tehuana faz referência às mulheres da cidade de Santo Domingo Tehuantepec, no estado de Oaxaca, no Sul do México. Esta sociedade, essencialmente matriarcal, é famosa pelos vestidos longos coloridos de renda, tão popularizados por Frida Kahlo.
} 
Podemos perceber que, em suas escolhas, a artista não opera ao nível da negação de um "apesar de" - de possível conotação heroica e sim de modo inclusivo. Dessa forma, até os dias atuais, inspira artistas plásticos, cineastas, dramaturgos, escritores de ficção e não-ficção e designers de moda.

Jean Paul Gaultier, em 1997, lançou a coleção de verão relendo os quadros autobiográficos de Frida. Ricardo Tisci, da Givenchy, também usou a sua paixão por Kahlo como inspiração na coleção do inverno de 2010. Ele transformou a anatomia humana em renda, ao fazer referência ao esqueleto quebrado e remendado da artista, que sofreu mais de trinta cirurgias no corpo. Em 2012, Moschino encheu a passarela de flores, estampas, tranças e cultura mexicana, honrando a mesma artista. No ano de 2013, em uma parceria com Fernanda Young e Alexandre Herchcovitch, Duda Molinos produziu o evento "Call me Frida", resgatando o feminino da pintora.
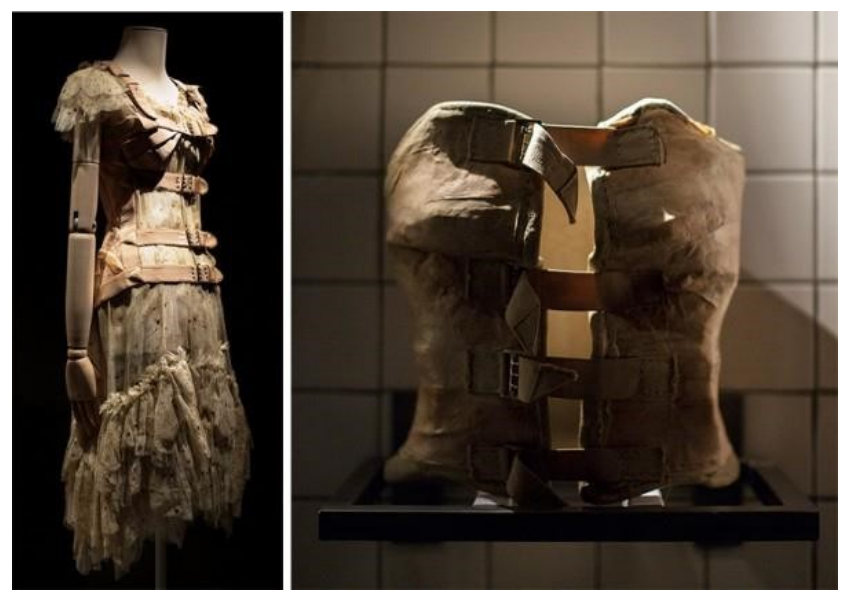

Figura 4: O vestido-corset de Gaultier, de 1994, foi inspirado nos usados durante a recuperação de Frida.

Fonte:<http://jualmsfotografia.blogspot.com.br/2013/03/o-guarda-roupa-de-frida-kahlo.html>.

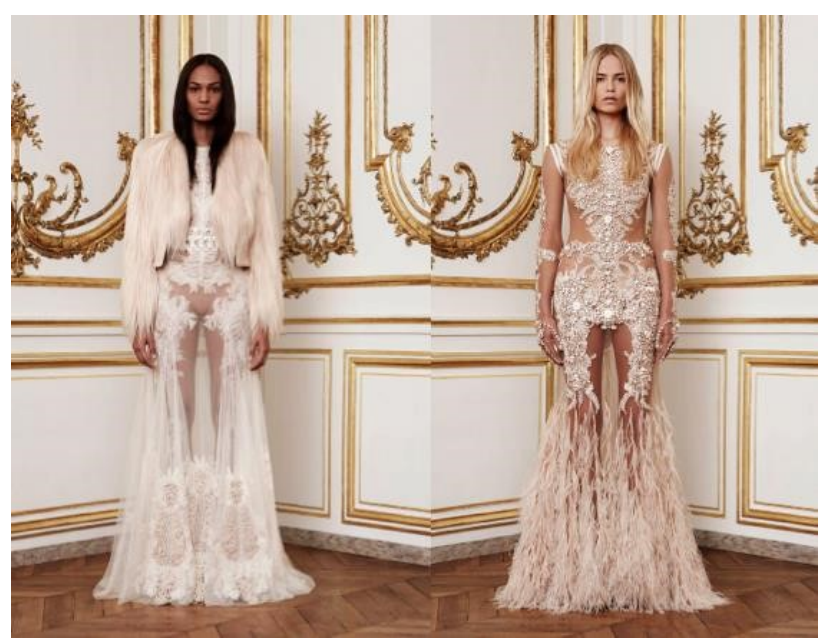

Figura 5: Peças da coleção de Ricardo Tidsy para Givenchy. Alta costura, inverno 2010.

Fonte: <(http://www.style.com/fashionshows/complete/F2010CTR-GIVENCHY> 
Ainda neste ano, o Museu de Frida Kahlo, situado na casa onde morava, Casa Azul, inaugurou uma exposição, "As aparências enganam", apenas com o guarda-roupa da pintora, que ficou guardado por quase cinquenta anos, e o qual podemos ver nas imagens abaixo:

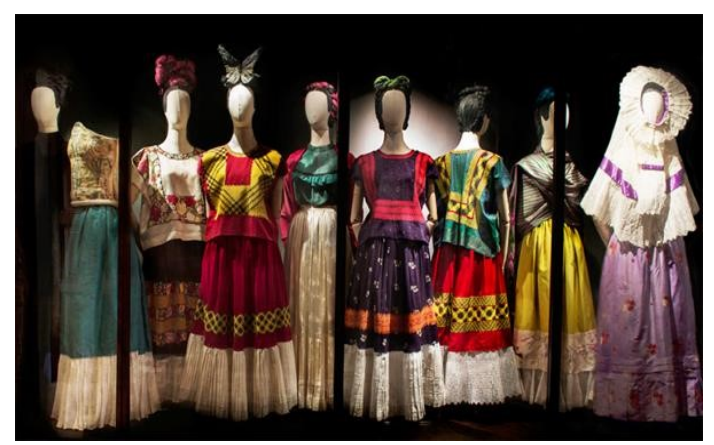

Figura 6: Exposição “As aparências enganam”.

Fonte:<(http://jualmsfotografia.blogspot.com.br/2013/03/o-guarda-roupa-de-frida-kahlo.html>.

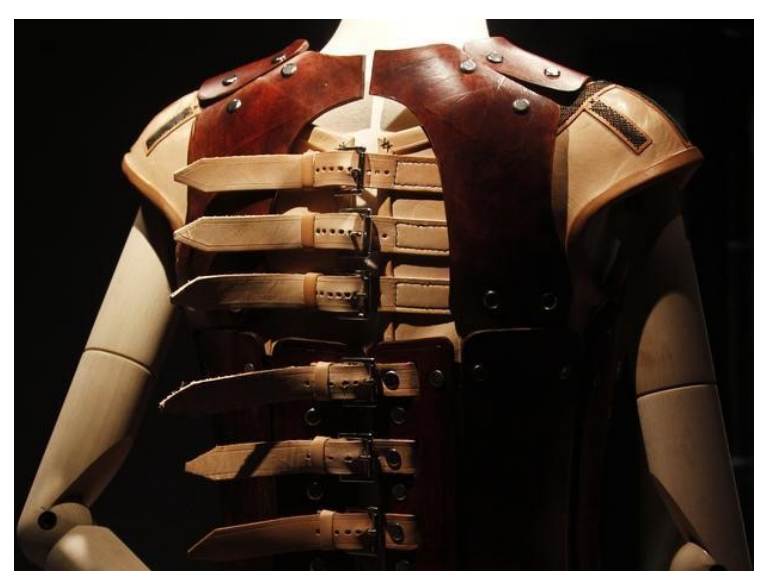

Figura 7: Guarda-roupa de Frida.

Fonte: <http://jualmsfotografia.blogspot.com.br/2013/03/o-guardaroupa-de-frida-kahlo.html>.

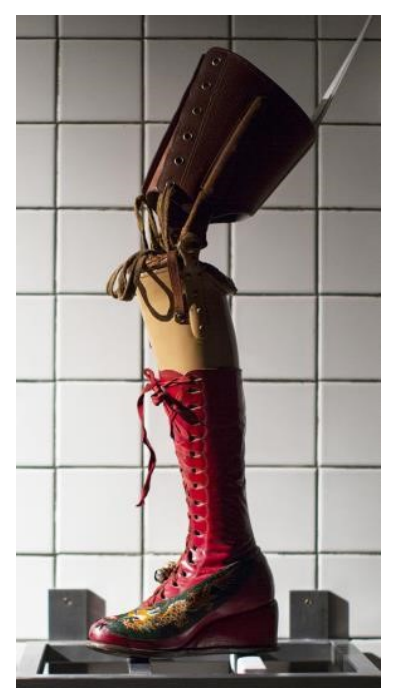

Figura 8: Guarda-roupa de Frida.

Fonte: <http://jualmsfotografia.blogspot.com.br/2013/03/o-guardaroupa-de-frida-kahlo.html>. 
Frida fez uso da roupa para tamponar um eu fragmentado, contraditório e fervilhante, e eternizando-se. Em cada criação emergiu um sujeito-criador, um sujeito do inconsciente, nesse universo, a criação, é fruto dessa relação de alteridade entre o sujeito e o objeto, o sujeito e o seu mundo, o sujeito e o desejo.

\subsection{Frida, a moda e a psicanálise}

Quando o "eu" se forma, ao perceber que não é exatamente igual ao outro, há uma perda, o ponto-cego nessa imagem é a falha da qual vai surgir o desejo singular. Se o eu fosse igual ao outro, haveria a satisfação, entretanto, essa infinita busca pela realização é a natureza incessante do desejo humano, do qual Frida, como tantos outros criadores, é um exemplo.

A moda assume seu lugar na busca da identidade do indivíduo como um desejo, encontrado através da roupa, a satisfação narcísica, um certo prolongar de uma sensação de controle sobre a própria imagem, correspondente à "imagem especular", assim, a manutenção da representação correspondente ao eu-ideal como uma montagem figurada no esquema óptico. No entanto, isso é um processo contínuo, pois o sujeito precisa se manter num movimento constante em direção aos "eus" que estão sempre fora de seu alcance e se apresentam, por sua vez, em constante renovação.

Nessa aparente contradição entre manutenção e movimento em busca de mudança, é importante ressaltar que criar em moda não significa acrescentar algo totalmente novo a um determinado recorte de mundo, mas de tornar evidentes os contornos de um mapeamento particular de algo que já está ali, que já faz parte do que costuma ser tomado como desejo em meio àquele grupo. Por isso é tão complexo o processo criativo; é preciso imaginar e reconhecer o campo vasto que estes personagens, para quem criamos e habitam, tanto no mundo quanto dentro de si.

A vestimenta e a moda podem também ser capazes de acionar, potencializar, nos sujeitos, processos criadores de novos modos de existir, novos modos de viver, novos estilos, novas formas de si, enfim, de fazer emergir singularidades. É dentro desse movimento e na constante busca de uma imagem idealizada e às vezes conturbada, que há a identificação, afinal, "o eu é um precipitado de identificações" (FREUD, 1923/1996).

Lacan, apresentou bases para a compreensão de que a criação de moda está formulada em seu pressuposto de que o psíquico não é um dado, mas sim uma construção. É algo que ganha uma organização estrutural e lógica logo no início da vida e que segue em permanente construção, em permanente transformação. Isso ocorre tanto no plano do sujeito do inconsciente, como no plano do eu - quando então o conceito de identificação, com todas as suas derivações e contextualização, eu-ideal e ideal-do-eu se desenvolvem dentro do registro do imaginário. As dimensões lacanianas do imaginário e do simbólico me permitem pensar a moda em relação ao tema da constituição do eu, narcisismo, estádio do espelho, eu-ideal e ideal-do-eu, na medida em que as vestimentas, as roupas que cobrem corpos podem ser vistos como aqueles traços imaginários que constituem o indivíduo. 
É possível extrair a ideia de que o processo do vestir e a moda podem funcionar como instrumentos de transformação e a roupa como um instrumento de identificação. Criar e refazer mais adiante, num contínuo "vir-a-ser".

\section{CONCLUSÃO}

Frida Khalo foi capaz de vivenciar um novo eu através da veste. Concebendo a imagem do corpo vestido como parte do próprio corpo, inspirado num mapeamento de forças colhidas do mundo e de suas vivências.

O diálogo entre quem inspira, quem cria e quem usa é uma forma de transformação para os sujeitos.

O criador, assiste seu trabalho em pleno processo de diluição, de atravessamentos, de fuga, de escape dos contornos delimitados por suas considerações iniciais e parâmetros ideais. A roupa produz imagens de desejo e reproduz o desejo do criador. Assim, o processo criativo, seria em primeiro lugar inspirado por um guia ideal criando-se um personagem imaginário para depois elaborar-se "uma moda", dar forma consequente ao que se veste.

O ser humano busca no vestir novas identificações, novas formas de eu, e a moda pode ser uma das vias para promover este encontro, para impactar com a surpresa do desejo até então desconhecido.

Em parte, o indivíduo é constituído a partir daquilo que veste e a roupa pode ser vista como seu invólucro, tecida com fios de sua memória, de suas escolhas, de seus desejos, portanto, o vestir e o ser tornam-se quase sinônimos quando procuramos entender suas relações.

\section{REFERÊNCIAS}

BADDELEY, Oriana. 'Her dress hangs here': De-frocking the Kahlo cult. Oxford Art Journal, vol. 14, no 1. Oxford University Press, 1991, pp.10-7. Disponível em: http://gen2.ca/DBHS/Art.1/1360274.pdf. Acesso em: 18 Jun. 2013.

FLORES, Laura González. As fotos da Casa Azul. In: MONASTERIO, Pablo Ortiz (org.). Frida Kahlo: suas fotos. São Paulo: Cosac \& Naify, 2010, pp.129-34.

FREUD, Sigmund. (1913 [1912-13]). Totem e tabu. In: Edição Standard Brasileira das Obras Completas de Sigmund Freud, vol. 13. Rio de Janeiro: Imago, 1996. . (1914). Sobre o narcisismo: uma Introdução. In: Edição Standard Brasileira das Obras Completas de Sigmund Freud, vol. 14. Rio de Janeiro: Imago, 1996. . (1921). Psicologia de grupo e a análise do ego. In: Edição Standard Brasileira das Obras Completas de Sigmund Freud, vol. 18. Rio de Janeiro: Imago, 1996. . (1923). O ego e o Id. In: Edição Standard Brasileira das Obras Completas de Sigmund Freud, vol. 19. Rio de Janeiro: Imago, 1996. (1900). A Interpretação dos Sonhos. Rio de Janeiro: Imago Editora, 2001. 
HERRERA, Hayden. Frida: a biography of Frida Kahlo. New York: Harper and Row, 1983.

KAHLO, Frida. O diário de Frida Kahlo: um autorretrato íntimo. Tradução: Mario Pontes. Rio de Janeiro: José Olympio, 2012.

LACAN, Jacques. (1949). O estádio do espelho como formador da função do eu. In: . (1966). Escritos. Rio de Janeiro: Jorge Zahar Editor, 1998, p.96-103. . (1953). Função e campo da fala e da linguagem em psicanálise. In:

(1966). Escritos. Rio de Janeiro: Jorge Zahar Editor, 1998, p.238-324.

. (1953-54). O Seminário, livro 1: os escritos técnicos de Freud. Rio de Janeiro: Jorge Zahar Editor, 1986.

. (1954-55). O Seminário, livro 2: o eu na teoria de Freud e na técnica da psicanálise. Rio de Janeiro: Jorge Zahar Editor, 2010.

Editor, 1985. (1955-56). O Seminário, livro 3: as psicoses. Rio de Janeiro: Jorge Zahar . (1959-60). O Seminário, livro 7: a ética da psicanálise. Rio de Janeiro: Jorge Zahar Editor, 1988.

(1964). O Seminário, livro 11: os quatro conceitos fundamentais da psicanálise. Rio de Janeiro: Jorge Zahar Editor, 2008. . (1966). Escritos. Tradução: Vera Ribeiro. Rio de Janeiro: Jorge Zahar Editor, 1998.

SOUZA, Eneida Maria. Crítica cult. Belo Horizonte: Ed. UFMG, 2002. 